Short Communication

\title{
Newborn Screening in Latin America: A Window on the Evolution of Health Policy
}

Jeffrey P. Brosco ${ }^{1,}{ }^{*}$, Talia Holzman Castellands ${ }^{2}$, Adriane Gelpi ${ }^{1}$

1. University of Miami, Miami 33101, FL, USA; E-Mails: jbrosco@miami.edu; agelpi@post.Harvard.edu

2. University of Illinois at Chicago, Chicago, IL, USA; E-Mail: talia@uic.edu

* Correspondence: Jeffrey P. Brosco; E-Mail: jbrosco@miami.edu

Academic Editors: Diane B. Paul and Ilana Löwy

Special Issue: Policy Issues in Prenatal and Neonatal Testing, Counseling, and Decision-Making

OBM Genetics

2022, volume 6 , issue 1

doi:10.21926/obm.genet.2201146
Received: August 22, 2021

Accepted: January 18, 2022

Published: January 21, 2022

\begin{abstract}
Investigating the historical origins of a well-accepted health program across a region, such as newborn screening in Latin America, has the potential to reveal the role of historically-specific drivers in shaping national health policy. We reviewed published reports on NBS in Latin America and interviewed newborn screening experts with experience in the region. We found trends suggesting that the decrease in infant mortality may be a prerequisite to investing in nationwide screening for rarer conditions. We also note the role of the International Atomic Energy Agency in boosting newborn screening programs in developing nations as a legacy of Cold War diplomacy to promote peaceful uses of atomic energy. Further research in charting demographic trends and in contrasting nations that engaged with the Agency with those that did not has the potential to reveal critical issues in health policy development.
\end{abstract}

\section{Keywords}

Newborn screening; policy; Latin America; PKU; history; atomic energy

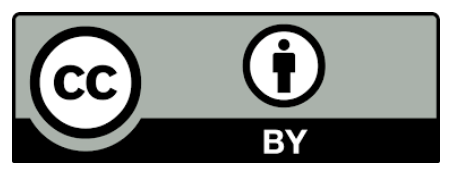

(C) 2022 by the author. This is an open access article distributed under the conditions of the Creative Commons by Attribution License, which permits unrestricted use, distribution, and reproduction in any medium or format, provided the original work is correctly cited. 
Newborn screening (NBS) for phenylketonuria (PKU) was implemented across the U.S. in the 1960s, and other conditions such as congenital hypothyroidism (CH) were added in the 1970s [1]. Over the last half-century, nations across the globe have started a NBS program, and thousands of infants are healthier because of NBS programs. There are substantial national differences, however, because NBS is a system, not just a screening test. For example, the number of conditions tested for in each nation varies depending on factors such as epidemiology, financing, logistics, politics, culture, and the attitudes and disciplinary backgrounds of health professionals [2].

We hypothesized that the history of NBS programs could be used to understand the development of health policy. As countries implement NBS, they could potentially have to negotiate among scientists and clinicians, families and self-advocates, and other interested parties such as pharmaceutical companies and scientific instrument manufacturers. How and when newborns are screened for different conditions in different countries thus reflects each nation's process for judging scientific evidence amid competing claims by stakeholders, with the tenacity and interpersonal ability of advocates often being crucial to success. We further hypothesized that by investigating the origins of NBS programs in several countries across a region, we would uncover broader themes not obvious when focusing on one nation.

In this brief report, we present the preliminary results of a review of published reports on NBS in Latin America, supplemented by interviews with NBS experts with experience in the region. We began with a Pubmed search using the terms "newborn screening" and the names of each country in Latin American. We then interviewed scholars we had identified as having published about NBS in the region. We used a semi-structured technique asking questions such as which countries they had most experience with, how NBS began in those nations, and whether they could recommend further resources or people to be interviewed. This "snowball" method led to additional search terms and people to be interviewed (list available from authors).

With more than 35 counties and territories, including Mexico and the Caribbean islands, Latin America has a population of approximately 650 million people and a wide diversity of approaches to NBS. Countries such as Costa Rica, Chile, and Uruguay have well-developed national NBS programs that reach most newborns and test for a wide variety of conditions. Other nations have university- or hospital-based NBS programs that test a limited number of newborns. Still others are just beginning NBS programs for single conditions, such as sickle cell disease in the Caribbean [3-5]. These national differences provide the opportunity for better understanding the development of NBS policy. Furthermore, the history of NBS is relatively understudied in the region, compared to the U.S., Europe, and the United Kingdom.

Not surprisingly, we found that particular, highly-motivated individuals in each nation played an outsize role in the establishment of NBS programs. Just as microbiologist Robert Guthrie is credited with translating his scientific work with PKU into statewide screening programs in the United States, individuals with scientific expertise-often linked to Dr. Guthrie and associates-advocated for NBS programs in each Latin American nation. These champions wrote about the benefits of NBS, cajoled colleagues, and sometimes led agencies responsible for health policy. For example, Erna Raimman at the University of Chile's Instituto de Nutrición y Tecnología de los Alimentos was instrumental in developing the NBS program in Chile.

Broader secular trends such as the general health of the population also influenced the development of NBS programs. In the United States, state NBS programs did not begin until the 1960s, when the infant mortality rate (IMR) fell below 30 deaths per 1000 live births. Even if the 
technology and knowledge had been available decades earlier, it is hard to imagine a nation investing in rare conditions such as PKU, which occurs only in 1 in 10,000 births, when 1 in 5 infants was dying of an infectious disease. Plotting the IMR of selected Latin American nations [6] over time (Figure 1) is instructive: the first national NBS programs began in Costa Rica (1990) and Chile (1992), after each country's IMR fell below 30. In contrast, national NBS came later in Mexico (1995) and Brazil (2001), when their IMR went below 30. Nations such as Guatemala, with a relatively high IMR, are still developing pilot NBS programs [4]. The association between initiation of a NBS program and lower IMR may mean that nations made an explicit health policy decision to start NBS only after reducing more common causes of infant mortality. Alternatively, the association between NBS and IMR could reflect a nation's overall economic development: as resources and infrastructure become more generally available in a society, nations have the wherewithal to implement highly technical population-based screening such as NBS. IMR has long been viewed as a measure of economic and political development $[7,8]$.

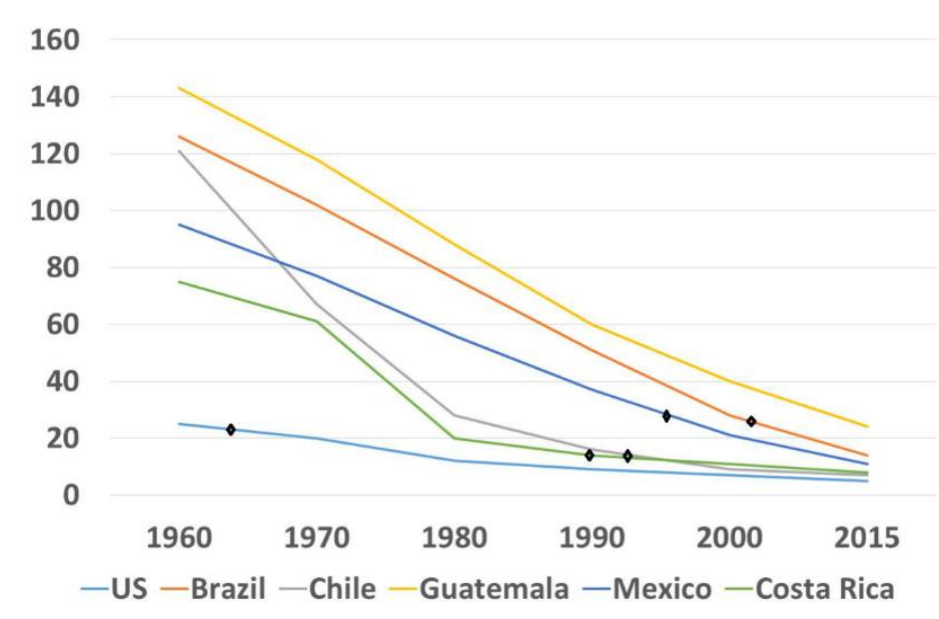

Figure 1 Infant Mortality Rate (deaths/1000 live births) in Selected Nations [6]. Diamond indicates approximate year NBS became widely available [2].

One striking contrast with the United States is that the development of many NBS programs in Latin America was driven by the desire to detect and treat hypothyroidism rather than PKU. This makes practical sense, as $\mathrm{CH}$ is one of the most common metabolic condition revealed by NBS (1:1700 to $1: 3600$ ) [9]. Hypothyroidism is also inexpensive and easy to treat, in further contrast to many other NBS conditions. Indeed, nearly every nation with a NBS program started with or includes $\mathrm{CH}$ as part of their panel, though Jean Dussault reports difficulty publishing initial research on the value of early detection and treatment of $\mathrm{CH}$ [10].

Our research revealed another, surprising reason for the role of $\mathrm{CH}$ as a target condition in the development of NBS programs in Latin America: the International Atomic Energy Agency (IAEA). In his "Atoms for Peace" speech to the United Nations General Assembly in 1953, U.S. President Eisenhower touted the civilian nuclear applications in power generation, agriculture, and medicine. One clinical example was the radioimmunoassay, discovered in 1957 and widely applied in the 1960s, including as a screening test for hypothyroidism [11].

Starting in the late 1980s, the IAEA worked with national laboratories to supply or support local production of the reagents, equipment for diagnosis, computer software, and training in quality 
control and safety procedures in more than 20 developing countries in Africa, Asia, and Latin America [12, 13]. For example, in 1990 the IAEA partnered with Uruguay's University of the Republic launch a NBS program for CH within the school's Nuclear Medical Center. This project led to efforts to expand early diagnosis of congenital diseases in children, including PKU and cystic fibrosis [14].

To confirm the findings of this brief report, more research with unpublished or less accessible resources, such as conference proceedings, is necessary. Furthermore, we chose to focus our analysis on when each nation began a large-scale, population-based approach to NBS for at least one condition; further research could include analyses of discrepancies in scope, access, and coverage. Despite these limitations, we conclude that investigating the historical origins of a wellaccepted health program across a region, such as NBS in Latin America, has the potential to reveal the role of historically-specific drivers in shaping national health policy. In particular, we found trends suggesting that the decrease in infant mortality may be a prerequisite to investing in nationwide screening for rarer conditions. Future research can examine policy discussions for confirmation that IMR was an explicit consideration among public health officials; another approach would compare initiation of NBS programs with measures of economic and political development that may also improve IMR. Even more revealing than the IMR association is the role of the IAEA to boost NBS programs in developing nations as a legacy of Cold War diplomacy to promote peaceful uses of atomic energy. Contrasting nations that engaged with the IAEA with those that did not has the potential to reveal critical issues in health policy development.

\section{Abbreviations}

$\begin{array}{ll}\text { IAEA } & \text { International Atomic Energy Agency } \\ \text { IMR } & \text { infant mortality rate } \\ \text { NBS } & \text { newborn screening } \\ \text { PKU } & \text { phenylketonuria }\end{array}$

\section{Acknowledgments}

The authors wish to thank the University of Miami Miller School of Medicine Institute for Bioethics and Health Policy, and in particular Dr. Kenneth W. Goodman for review of the manuscript. We benefited from feedback received after an early version of this paper was presented at the annual Conference of the American Association for the History of Medicine in May 2017, as well as from anonymous reviewers in 2020 and 2021. Diane Paul and Ilana Lowy offered valuable suggestions on the manuscript. Lastly, we thank the NBS experts who donated their time in interviews to help us better understand screening programs in Latin America.

\section{Author Contributions}

JPB conceptualized and designed the study, analyzed the data, drafted the initial manuscript, and reviewed and revised the manuscript. AG conceptualized and designed the study, coordinated and supervised data collection, analyzed the data, and reviewed and revised the manuscript. THC designed the data collection instruments, collected data, carried out the initial analyses, and reviewed and revised the manuscript. 


\section{Funding}

No funding was secured for this research.

\section{Competing Interests}

The authors have declared that no competing interests exist.

\section{References}

1. Paul DB, Brosco JP. The PKU paradox: A short history of a genetic disease. Baltimore: Johns Hopkins University Press; 2013.

2. Therrell BL, Padilla CD, Loeber JG, Kneisser I, Saadallah A, Borrajo GJ, et al. Current status of newborn screening worldwide: 2015. Semin Perinatol. 2015; 39: 171-187.

3. Queiruga G. Neonatal screening-its importance and impact in Latin America. J Int Fed Clin Chem Lab Med. 2015; 26: 326-331.

4. Borrajo GJ. Newborn screening in Latin America at the beginning of the 21st century. J Inherit Metab Dis. 2007; 30: 466-481.

5. Knight-Madden J, Lee K, Elana G, Elenga N, Marcheco-Teruel B, Keshi N, et al. Newborn screening for sickle cell disease in the Caribbean: An update of the present situation and of the disease prevalence. Int J Neonatal Screen. 2019; 5: 5.

6. HumanProgress. Infant mortality rate-per 1,000 live births, 1960-2019 [Internet]. Washington: HumanProgress; [cited 2017 April 30th]. Available from: http://humanprogress.org/story/2386?gclid=CjwKEAjwlpbIBRCx4eT819W26igSJAAuQ HGMg5zV1TG -WbiFHzITHTuzFTVkuXgj8d7VGDR2fohoCwSrw wcB.

7. Brosco JP. The early history of the infant mortality rate in America: "A reflection upon the past and a prophecy of the future" ${ }^{11}$. Pediatrics. 1999; 103: 478-485.

8. O'Hare B, Makuta I, Chiwaula L, Bar-Zeev N. Income and child mortality in developing countries: A systematic review and meta-analysis. J R Soc Med. 2013; 106: 408-414.

9. Therrell BL. Screening of newborns for congenital hypothyroidism: Guidance for developing programmes. Vienna: International Atomic Energy Agency; 2005.

10. Dussault JH. The anecdotal history of screening for congenital hypothyroidism. J Clin Endocrinol Metab. 1999; 84: 4332-4334.

11. Kuyl JM. The evolution of thyroid function tests. J Endocrinol Metab Diabetes S Afr. 2015; 20 : 11-16.

12. International Atomic Energy Agency. Screening newborns for health: Simple, cost-effective nuclear technique prevents mental retardation in developing countries [Internet]. Vienna: International Atomic Energy Agency; 2018. Available from: https://www.iaea.org/newscenter/pressreleases/screening-newborns-health-simple-costeffective-nuclear-technique-prevents-mental-retardation-developing-countries.

13. Solanki KK. Training programmes for developing countries. J Inherit Metab Dis. 2007; 30: 596599.

14. International Atomic Energy Agency. Screening for congenital abnormalities in newborns, Uruguay [Internet]. Vienna: International Atomic Energy Agency; 2008. Available from: https://www.iaea.org/sites/default/files/documents/tc/Succ Stories_TCLA.ppt. 


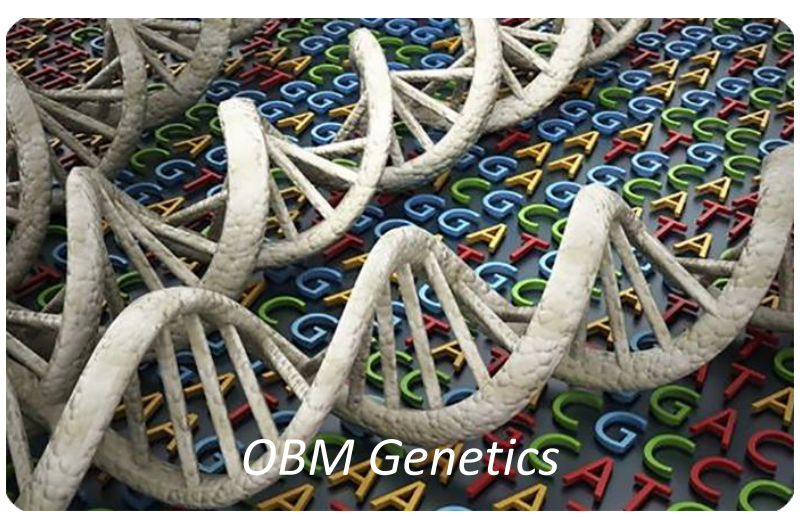

Enjoy OBM Genetics by:

1. Submitting a manuscript

2. Joining in volunteer reviewer bank

3. Joining Editorial Board

4. Guest editing a special issue

For more details, please visit:

http://www.lidsen.com/journals/genetics 